\title{
PERCEPÇÃO AMBIENTAL DOS RESIDENTES DO BAIRRO PRESIDENTE MÉDICI EM CAMPINA GRANDE-PB, NO TOCANTE À ARBORIZAÇÃO LOCAL
}

\author{
Jussiara de Lima Oliveira Araújo ${ }^{1}$, Afrânio César de Araújo ${ }^{2}$, Ariosto Céleo de Araújo ${ }^{3}$
}

(recebido em 02.02.2010 e aceito para publicação em 10.06.2010)

\section{RESUMO}

As árvores urbanas proporcionam sombra, redução da poluição sonora e do impacto da água de chuva, contribuem na diminuição da temperatura e melhoram a qualidade do ar. A percepção ambiental tem auxiliado na compreensão das expectativas, satisfações e insatisfações das populações no tocante ao meio e aos elementos relacionados à qualidade de vida e bem estar social. Objetivou-se, com este trabalho, avaliar a percepção dos moradores do bairro Presidente Médici em relação à arborização local, avaliando o grau de conhecimento da comunidade no tocante à importância das árvores, preservação e correto manejo. Foi utilizado um questionário previamente elaborado contendo questões que abordaram as seguintes temáticas: número de moradores por residência, escolaridade, nível de arborização da rua, importância da arborização, fatores positivos e negativos da arborização, colaboração para com a arborização, manutenção e melhoria da arborização, conhecimento de espécies indicadas para calçadas. Os moradores entrevistados demonstraram conhecer os benefícios da arborização bem como a preocupação em manter as árvores existentes e colaborar para a ampliação da área verde na região. Os problemas identificados podem ser minimizados a partir de ações educativas como a distribuição de folhetos informativos.

Palavras-chave: arboricultura, percepção ambiental, silvicultura urbana.

\footnotetext{
${ }^{1}$ Bióloga, Especialista em Educação Ambiental, UEPB/CCBS, Campina Grande, PB, email: jussiaralima@hotmail.com.

${ }^{2}$ Biólogo, Msc. em Agronomia, UFRN, Macaíba, RN, email: afraniobiologo@hotmail.com.
}

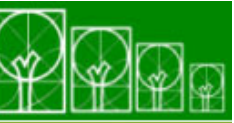

S $\cdot \mathbf{B} \cdot \mathbf{A} \cdot \mathbf{U}$ Soc. Bras. de Arborização Urbana , 2010 
${ }^{3}$ Acadêmico de Agronomia, UFPB/CCA, Areia, PB, Email: arisabbath@hotmail.com.

ENVIRONMENTAL PERCEPTION OF PRESIDENTE MÉDICI NEIGHBORHOOD RESIDENTS, CAMPINA GRANDE-PB, ABOUT THE LOCAL URBAN FOREST

\section{ABSTRACT}

The urban trees provide shade, reduction on sound pollution and rain water impact, contribute in temperature decrease and improve the air quality. The environmental perception have been helped to understand expectations, satisfactions and dissatisfactions of populations related to environment and elements of life quality and social welfare. The aims of this work were evaluate the perception of Presidente Médici neighborhood residents related to local trees, community knowledge degree about trees importance and its preservation and correct management. A questionnaire containing objective and discursive questions was used approaching the following issues: people number by home, educational level, streets urban forest level, urban forest importance, positive and negative factors of urban forest, collaboration of residents with urban forest, urban forest maintenance and improvement, knowledge about indicated species for planting on sidewalks. The interviewed people showed know the urban forest benefits as well as the concern to maintain the existing trees and collaborate to increase the green area in the region. The identified problems could be minimized by educational actions as well as the distribution of informative literature about correct tree planting and maintenance.

Keywords: arboriculture, environmental perception, urban forestry 


\section{INTRODUÇÃO}

Entende-se por arborização urbana, toda vegetação, predominantemente arbórea, que ocupa os espaços livres públicos e privados de uma cidade. Constituem a área urbana de uma cidade: áreas edificadas, tais como casas, estabelecimentos de comércio e indústrias, áreas destinadas à circulação da população, como o sistema rodo-ferroviário, além das áreas verdes de edificação (praças, quintais, etc.) (OKAMOTO, 2002).

As árvores urbanas reúnem características que contribuem para a melhoria das condições de vida da população nos centros urbanos, pois proporcionam benefícios como bem estar psicológico, sombra, redução da poluição sonora e do impacto da água da chuva, contribuem na diminuição da temperatura, melhoram a qualidade do ar e preservam a fauna silvestre (PIVETTA e SILVA FILHO, 2002).

As árvores urbanas crescem em importância na medida em que as cidades se expandem, já que propiciam conforto ambiental e melhora na qualidade de vida. Para isto, no entanto, a arborização deve ser bem planejada a fim de que a vegetação cumpra suas funções ecológicas, econômicas e sociais, buscando-se a minimização dos impactos adversos incidentes no ecossistema urbano e propicie melhorias no padrão sócio-ambiental (LIRA FILHO et al., 2006).

Entende-se por percepção ambiental o ato do ser humano perceber o ambiente no qual se insere e aprender a protegê-lo; é a tomada de consciência no tocante ao meio ambiente. A percepção, reação e resposta de cada indivíduo às ações sobre o meio em que vive é diferente e destas resultam manifestações individuais e coletivas oriundas dos processos cognitivos, julgamentos e expectativas de cada pessoa (ROPPA et al., 2007).

A percepção ambiental tem se destacado como técnica que associa a Psicologia com a Sociologia e a Ecologia e auxiliado na compreensão das expectativas, satisfações e insatisfações das populações no tocante ao meio e aos elementos relacionados à qualidade de vida e ao bem estar social. Sendo assim, o estudo da percepção ambiental assume importância para a compreensão das inter-relações entre o homem e o ambiente, bem como suas expectativas, anseios, satisfações e insatisfações, julgamentos e condutas. (TRIGUEIRO, 2003).

De acordo com Oliveira (2005), a percepção ambiental engloba o inter-relacionamento entre o comportamento e o ambiente, considerando tanto o ambiente como a paisagem urbana.

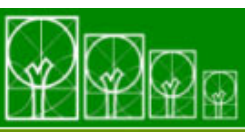

$\mathbf{S} \cdot \mathbf{B} \cdot \mathbf{A} \cdot \mathbf{U}$ Soc. Bras. de Arborização Urbana 
Objetivou-se, com este trabalho avaliar a percepção dos moradores do bairro Presidente Médici, Campina Grande, PB em relação à arborização local, identificando o seu nível de conhecimento no tocante à importância das árvores urbanas, preservação e correto manejo para posterior discussão e difusão de informações técnicas relevantes.

\section{MATERIAL E MÉTODOS}

O presente trabalho foi realizado no bairro Presidente Médici, localizado na zona sul da cidade de Campina Grande, Paraíba. O bairro tem uma população total de 4.145 habitantes, cuja renda per capita é de 3,12 salários mínimos e a taxa de alfabetização em torno de 92,90\%. (IBGE, 2002)

A intervenção foi do tipo ação-participante. A metodologia empregada para realização do presente trabalho baseou-se em um questionário previamente elaborado contendo questões objetivas e dissertativas, as quais foram apresentadas aos moradores do bairro (Tabela 1).

TABELA 1- Questionário de avaliação apresentado aos moradores do bairro Presidente Médici, Campina Grande, PB.

\section{Questionário de avaliação sobre arborização dos moradores do bairro Presidente Médici}

Rua:

Data:

\section{1- Sexo do entrevistado.}

( ) masculino

( ) feminino

\section{2- Qual o seu nível de escolaridade?}

( ) analfabeto

( ) ensino fundamental incompleto

( ) ensino fundamental completo

( ) ensino médio incompleto

( ) ensino médio completo

( ) ensino superior incompleto 


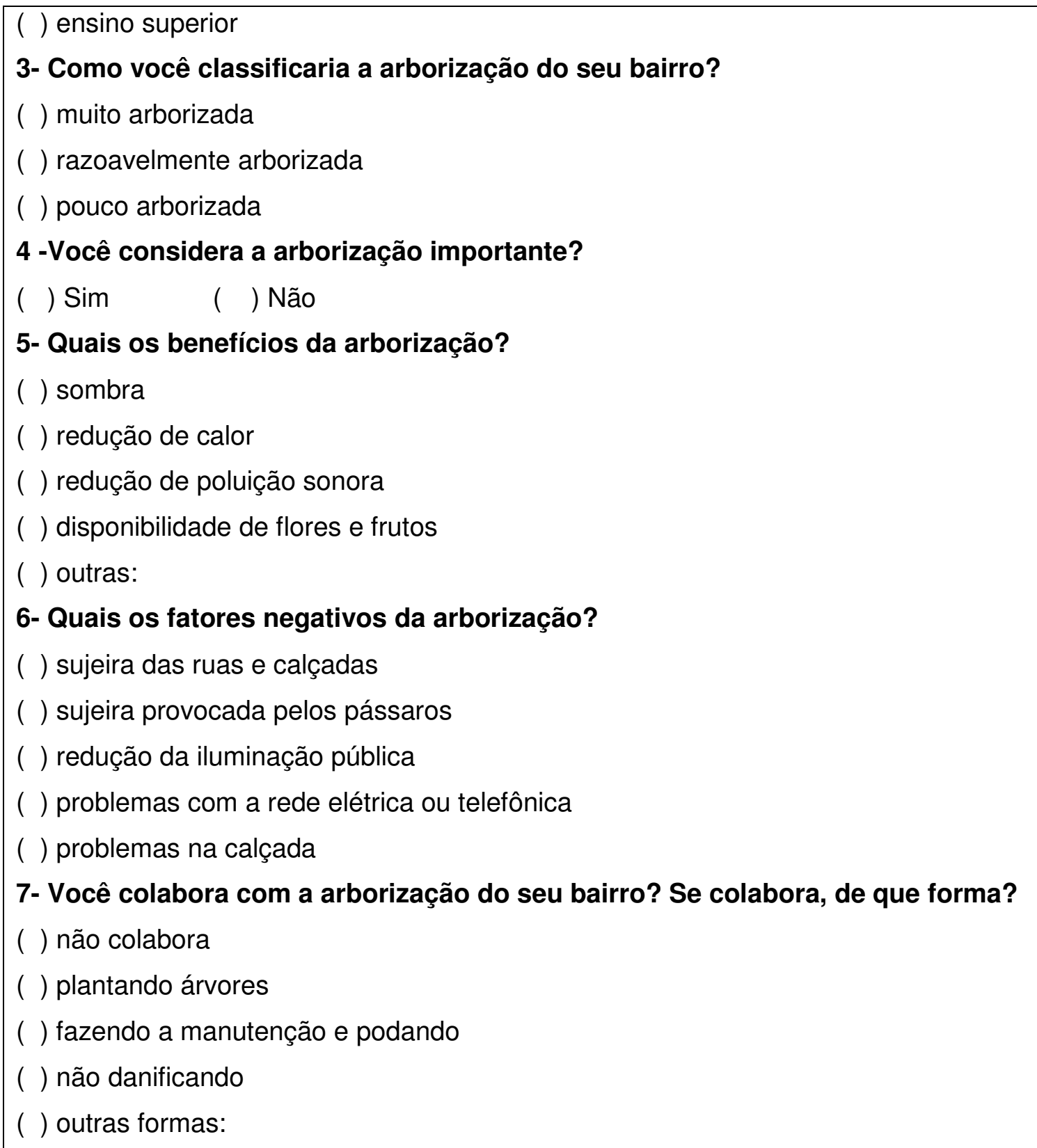

8- Você acha que as podas realizadas nas árvores do seu bairro são executadas de forma correta?
( ) Sim
( ) Não

9- 0 que poderia ser feito para melhorar a arborização de seu bairro?

( ) plantar mais árvores

( ) fazer manutenção e realizar podas de forma adequada e em época correta

( ) realizar um trabalho de conscientização ecológica sobre arborização

( ) outras formas:

10. Você apoiaria uma lei que obrigasse cada família a plantar e manter uma 


\section{árvore em sua residência?}

( ) Sim ( ) Não

11- Qual tamanho da área livre que deve ser deixada para a árvore?

( ) Mais de $1 \mathrm{~m}^{2}\left(\right.$ ) $1 \mathrm{~m}^{2}$ ( ) 0,5 $\mathrm{m}^{2}$ ( ) não precisa de área livre

12- Você pintaria com cal a porção inferior de uma árvore? Por que?

( ) $\operatorname{Sim} \quad($ ) Não

13- Que espécies de árvores você considera adequadas para serem plantadas em calçadas?

A aplicação dos questionários seguiu o método da amostragem aleatória, tendo sido aplicados a moradores de dez casas em cada uma de dez ruas amostradas, totalizando 100 questionários preenchidos.

Com base nas respostas dos moradores, obtidas na primeira visita, foi elaborado um panfleto informativo com orientações técnicas referentes à arborização, o qual foi entregue aos entrevistados mediante explanações acerca das informações nele contidas.

O panfleto foi elaborado de acordo com manuais técnicos, artigos e livros especializados.

\section{Recursos Utilizados}

- Recursos Humanos - 1 pesquisadora de campo;

- Material de Consumo - papel A4, caneta, prancheta;

- Recursos Didáticos - Manuais e revistas especializadas.

- Panfletos Informativos.

\section{RESULTADOS E DISCUSSÃO}

Dos 100 moradores entrevistados, $75 \%$ eram do sexo feminino e $25 \%$ do sexo masculino, o que está relacionado ao fato da maioria dos homens estarem no trabalho no momento da entrevista. 
Em relação ao nível de escolaridade dos entrevistados, foi verificado um número bastante significativo de pessoas que concluíram o ensino médio (40\%), seguidas dos moradores com ensino fundamental completo (16\%). Apenas $11 \%$ dos entrevistados possuíam ensino superior (Tabela 2). A amostra estatística foi formada, portanto, por pessoas letradas que, teoricamente, têm ou tiveram acesso a informações básicas fundamentais acerca dos benefícios da arborização urbana para as pessoas.

TABELA 2. Nível de escolaridade dos moradores, entrevistados, do bairro Presidente Médici, Campina Grande, PB.

\begin{tabular}{lc}
\hline ESCOLARIDADE & FREQUÊNCIA (\%) \\
\hline Não Alfabetizado & 0,0 \\
Ensino Fundamental Incompleto & 13,0 \\
Ensino Fundamental Completo & 16,0 \\
Ensino Médio Incompleto & 12,0 \\
Ensino Médio Completo & 40,0 \\
Ensino Superior Incompleto & 8,0 \\
Ensino Superior Completo & 11,0 \\
\hline
\end{tabular}

Quando os entrevistados foram convidados a classificar a arborização de seu bairro no tocante ao número relativo de espécies, os resultados foram: muito arborizada (23\%), razoavelmente arborizada (39\%) e pouco arborizada (38\%). Sendo assim, verifica-se que a maioria dos moradores não se encontrava satisfeita com a arborização das ruas do bairro Presidente Médici, considerando, pois, reduzido o número de árvores presentes na região.

A UNESCO indica como ideal para uma boa qualidade de vida uma relação de duas árvores para cada habitante ou $12 \mathrm{~m}^{2}$ de área verde por pessoa. No entanto, a cidade de Campina Grande possui uma média de 0,08 árvores por habitantes (DANTAS e SOUZA, 2004), o que revela que a cidade apresenta índices muito abaixo do recomendado.

Todos os entrevistados consideravam a arborização importante para os seres humanos. Dentre os benefícios da arborização, discriminadas no questionário, o fator sombra foi o que predominou na opinião dos moradores (60\%), seguido de redução de calor (24\%), redução da poluição sonora (10\%) e disponibilidade de flores e frutos (6\%) (Figura 1). 


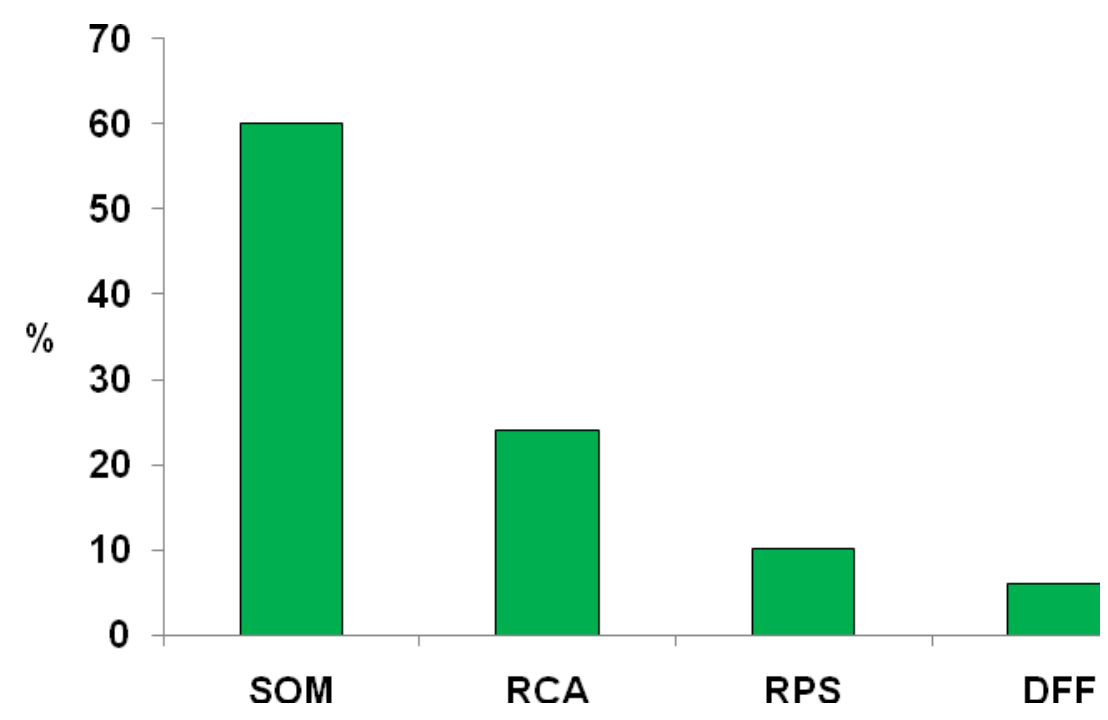

FIGURA 1- Benefícios da arborização urbana indicados pelos moradores do Bairro Presidente Médici, considerando Sombra (SOM), Redução de Calor (RCA), Redução da Poluição Sonora (RPS) e Disponibilidade de Flores e Frutos (DFF)

Apesar da vegetação não poder controlar totalmente as condições de desconforto no tocante ao calor, ela pode, de modo eficiente abrandar a sua intensidade (SANTOS e TEIXEIRA, 2001). Os entrevistados também destacaram que a vegetação arbórea proporciona índices mais elevados de umidade do ar, principalmente no verão, quando as plantas encontram-se com a folhagem, responsável pela transpiração e ainda diminuem as concentrações de dióxido de carbono da atmosfera.

Uma quantidade muito pequena de pessoas indicou as flores e os frutos como benefícios da arborização, o que demonstra o pouco conhecimento sobre a importância desses elementos para a alimentação e abrigo da avifauna urbana.

Com relação aos fatores negativos da arborização, a sujeira deixada em ruas e calçadas e problemas com a rede elétrica e telefônica somaram 64\% (Figura 2). 


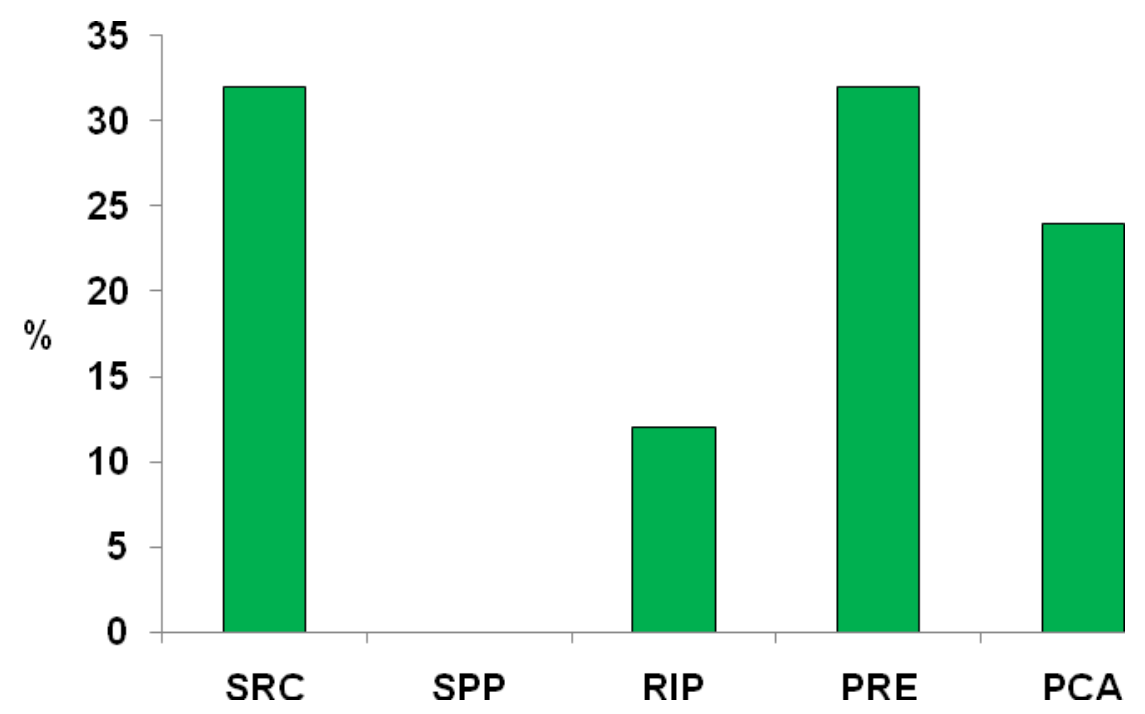

FIGURA 2- Fatores negativos da arborização indicados pelos moradores do Bairro Presidente Médici, considerando Sujeira de Ruas e Calçadas (SRC), Sujeira Provocada pelos Pássaros (SPP), Redução da lluminação Pública (RIP), Problemas com a Rede Elétrica e Telefônica (PRE) e Problemas nas Calçadas (PCA).

Os transtornos citados pelos moradores podem ser evitados quando a arborização de uma área é conduzida por pessoas que apresentam conhecimento técnico. Segundo o manual de arborização urbana da Cemig (2004), as árvores a serem plantas em calçadas onde existe rede elétrica devem ser de espécies de pequeno porte e deve-se manter uma distância em relação ao poste de, no mínimo 4 metros. Em calçadas sem rede elétrica podem ser utilizadas espécies de médio a grande porte.

Em relação ao tipo de colaboração dos moradores entrevistados, a maioria respondeu que colabora plantando árvores (35\%). Os demais responderam que colaboram fazendo manutenção e podando (24\%), não danificado (26\%) e (15\%) afirmaram não colaborar de forma alguma (Figura 3). 


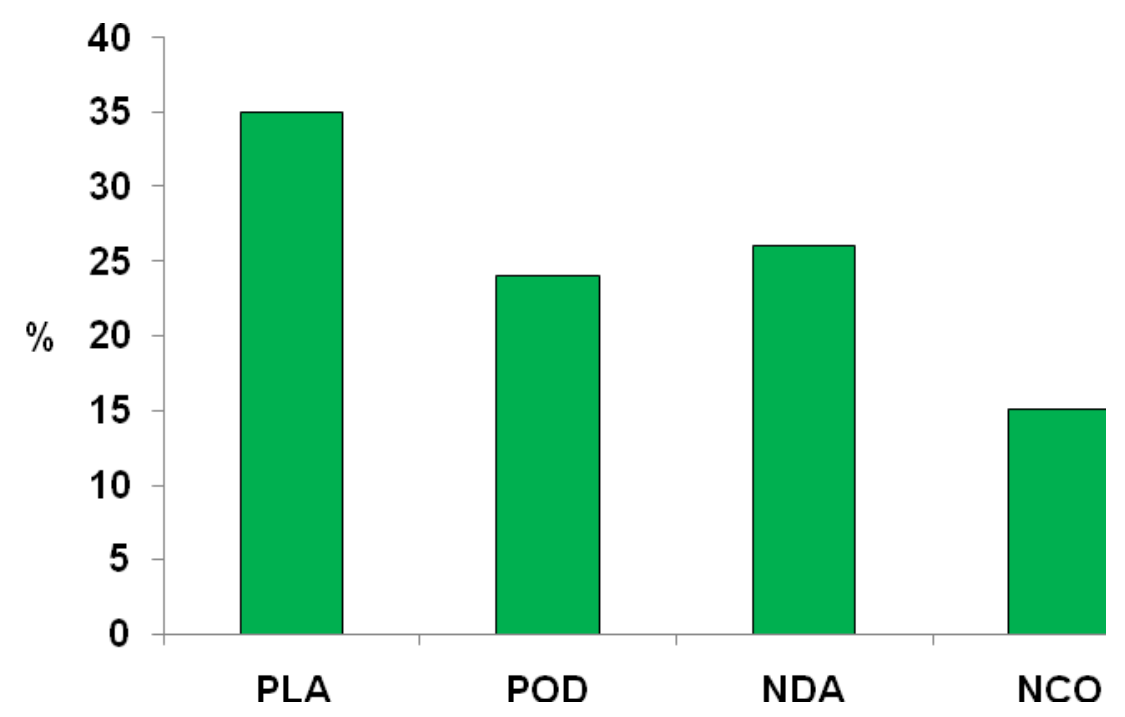

FIGURA 3- Formas com que os moradores do Bairro Presidente Médici afirmaram colaborar com a arborização de suas ruas: Plantando Árvores (PLA), Fazendo Manutenção e Podando (POD), Não Danificando (NDA) e Não Colaboram de Forma Alguma (NCO).

Foi verificado ao longo das entrevistas que as pessoas que afirmaram colaborar com a arborização plantando árvores, na verdade plantaram árvores não recomendadas para calçadas, provocando assim, transtornos que em muitos casos já se fazem presentes. No bairro estudado, são comuns Ficus benjamina L. e Cassia siamea (Lam.) H.S. Irwin e R.C. Barneby, espécies exóticas de grande porte que podem causar problemas consideráveis a estruturas diversas.

Quando questionados se as podas conduzidas na cidade eram realizadas de forma correta, a maioria (67\%), respondeu que não e 33\% disseram que sim. De acordo com Araújo et al. (2009), em inventário realizado no mesmo bairro, as maiores causas de danos aos vegetais de porte arbóreo no bairro Presidente Médici são as podas equivocadas, o que geralmente ocorre como reflexo da utilização de espécies inadequadas. A maior parte dos entrevistados acredita que as podas são um elemento positivo para o vegetal, o que propiciaria rebrota vigorosa seguida de formação de uma copa mais "vistosa e sadia". Muitos moradores justificam as podas drásticas afirmando que a sua realização retarda os problemas gerados por uma copa demasiado extensa, o que acaba contrariando um dos principais benefícios da arborização: fornecimento de sombra. Se o que mais interessa para a maioria dos moradores é a sombra proporcionada pelas árvores (Figura 1) a supressão consciente deste fator pela maior parte do ano evidencia-se como algo contraditório.

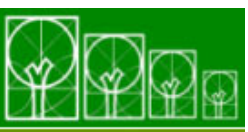

$\mathbf{S} \cdot \mathbf{B} \cdot \mathbf{A} \cdot \mathbf{U}$ Soc. Bras. de Arborização Urbana 
Segundo Silva et al., (2006), podas, drásticas podem reduzir o tempo de vida das árvores, já que, quando da sua realização, um grande número de raízes de pequeno calibre tem a sua eficiência reduzida, além do mais, a copa é danificada, o que deixa a árvore exposta ao ataque de pragas e doenças em função estresse fisiológico gerado (CASTRO, 2004).

A Poda se constitui num processo traumático à planta e provoca maior dano quando é realizada em épocas de maior atividade metabólica, como a floração. Sendo assim, só deve ser realizada nas ocasiões em que a atividade metabólica da árvore é menor (SITZ, 1996).

$\mathrm{Na}$ opinião dos entrevistados, para melhorar a qualidade da arborização de suas ruas poderiam ser plantadas mais árvores (40\%), fazer a manutenção e realizar podas de forma correta e em épocas adequadas (15\%). Cerca de $45 \%$ dos entrevistados sugere um trabalho de conscientização ecológica sobre arborização (Figura 4).

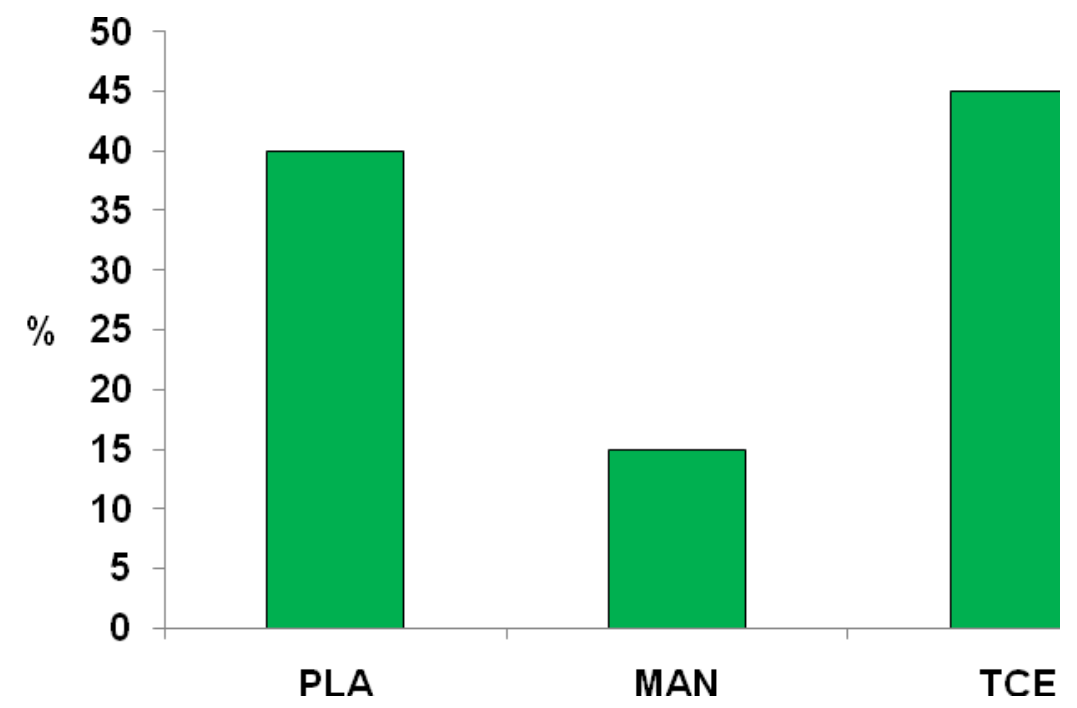

FIGURA 4- Atitudes citadas pelos moradores entrevistados do bairro Presidente Médici, Campina Grande, PB para melhorar a arborização.

Percebe-se que há interesse da população em ampliar e melhorar a comunidade arbórea do bairro estudado, bem como conduzir os processos de manutenção deste patrimônio. Nota-se ainda, interesse por despertar nos demais moradores a consciência da importância das árvores urbanas, o que poderia ser realizado a partir de um trabalho de educação ambiental.

Os moradores, em sua maioria, apóiam a idéia de todos plantarem árvores e reconhecem a sua importância, mas se dividem quando à criação de uma lei que exija que todos possuam uma árvore em sua residência (50\% apoiariam e 50\% não apoiariam). 
De acordo com a lei 7.803/89, art. 2, parágrafo único do Código Florestal as prefeituras municipais devem manter e executar a arborização urbana, porque essa competência deve estar prevista nos planos diretores e leis do uso do solo dos municípios, enfatiza Malavasi e Malavasi (2001), porém, nada impede que cada um faça sua parte e plante árvores em suas residências, desde que busquem informações técnicas sobre o tema.

De acordo com $50 \%$ entrevistados, a área livre a ser deixada nas calçadas para as árvores deve ser de $1,0 \mathrm{~m}^{2}$ enquanto que $30 \%$ responderam que o ideal seria de $0,5 \mathrm{~m}^{2}$. Os que citaram uma área superior a 1,0 $\mathrm{m}^{2}$ perfizeram $20 \%$ dos moradores entrevistados.

Apesar da maioria dos moradores defenderem uma área livre igual ou superior a 1,0 $\mathrm{m}^{2}$, estudos realizados por Araújo et al. (2009) no mesmo bairro mostraram que a área livre deixada para espécies de porte arbóreo não era satisfatória: 35,93\% foi considerada regular $\left(0,5-1,0 \mathrm{~m}^{2}\right) ; 31,44 \%$ foi considerada restrita (menor que $\left.0,5 \mathrm{~m}^{2}\right) ; 7,78 \%$ foi considerada inexistente e apenas $24,85 \%$ apresentou área livre ampla (superior a 1,0 $\mathrm{m}^{2}$ ) sendo, pois, classificada como satisfatória.

De modo a evitar danos provocados pelo sistema radicular das árvores, os planos de arborização das cidades devem respeitar a área livre mínima de $1,00 \mathrm{~m}^{2}$, inclusive para que possa ser realizada a irrigação e a adubação periódica (Pivetta e Silva Filho, 2002; Coelba, 2002). Além do mais, as raízes superficiais sofrem com áreas livres reduzidas, pois o aproveitamento de água, oxigênio e nutrientes é minimizado. (VOLPE-FILIK et al., 2007).

Quando os moradores foram questionados se pintariam a porção inferior do caule de suas árvores com cal, procedimento muito comum nas cidades brasileiras, a maioria (62\%) respondeu que não o faria pelos mais variados motivos, dentre os quais, a quebra da harmonia estética ou possibilidade de causar danos aos vegetais. Os restantes $38 \%$ disseram que pintariam por acreditarem que a árvore fica, segundo eles próprios, "mais bonita".

Segundo a Secretaria Municipal do Meio Ambiente de Ribeirão Preto/SP (1995) não é recomendado pintar o tronco das árvores, pois a cal (material mais usado) é tóxica para vários organismos, em especial, os liquens, associação de fungos e algas que vivem nos troncos das árvores.

De acordo com os moradores, as árvores mais indicadas para plantar em calçadas seriam: Fícus (Ficus benjamina L.) (56\%), Algaroba (Prosopis juliflora (SW.) D.C.) (1,0\%), Cássia amarela (Cassia siamea (Lam.) H.S. Irwin e R.C. Barneby (2,0\%) e Sombreiro (Clitoria fairchildiana R.A. Howard) (1,0\%). Segundo 19,0\% dos entrevistados, qualquer árvore poderia ser plantada e $20,0 \%$ não souberam responder. De fato, boa parte das

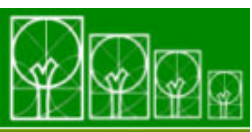

$\mathbf{S} \cdot \mathbf{B} \cdot \mathbf{A} \cdot \mathbf{U}$ Soc. Bras. de Arborização Urbana 
árvores do Bairro Presidente Médici é da espécie F. benjamina L., totalizando 51,95\%, conforme ressaltam Araújo et al., (2009). De acordo com Lorenzi et al. (2003), F. benjamina e C. siamea são árvores exóticas de tronco robusto e raízes vigorosas, podendo atingir altura superior a $15,00 \mathrm{~m}$ e são bastante comuns na arborização de cidades em todo o Nordeste, no entanto, podem provocar sérios danos a calçadas, pavimentos e edificações.

Os panfletos contendo técnicas básicas de arborização, distribuídos, causaram bastante satisfação entre os moradores. Estes se mostraram simpáticos às novas informações e demonstraram interesse em aplicar e difundir os conhecimentos recém adquiridos com vistas à conservação e ampliação da arborização local. De acordo com Pádua e Tabanez (1998), a educação ambiental promove a ampliação de conhecimentos, mudança de valores e aperfeiçoamento de habilidades, sendo estas as condições fundamentais para estimular maior integração e harmonia dos indivíduos com o meio ambiente.

\section{CONCLUSÕES}

Os moradores do bairro, independentemente do nível de escolaridade, reconhecem a importância da arborização para a melhoria da qualidade de vida nas cidades.

Muitos acreditam que uma árvore plantada defronte de suas casas é importante, visto que as altas temperaturas do verão podem ser amenizadas com a sua presença.

A maioria dos fatores negativos da arborização citados pelos moradores, quando ocorrem, são conseqüência da falta de informação da população no que se refere à escolha de espécies e manejo.

A distribuição de panfletos com informações básicas sobre a arborização urbana pode ser uma iniciativa preciosa e uma ferramenta importante para a reestruturação da arborização de muitas cidades.

\section{REFERÊNCIAS BIBLIOGRÁFICAS}

ARAúJO, A. C. de; RIBEIRO, I. A. M.; MORAIS, M. dos S.; ARAÚJO, J. de L. O. Análise quali-quantitativa da arborização no bairro Presidente Médici, Campina Grande-PB. Revista da Sociedade Brasileira de Arborização Urbana. v.4, n.1, p.133-134, 2009.

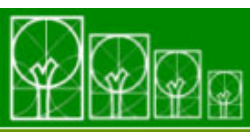

S · B · A : U Soc. Bras. de Arborização Urbana 
CASTRO, N.S. Arborização Urbana: poda, condução e legislação. São Paulo: SBAU, ano XII, n.1, 2004. 12 p. (Boletim informativo). Disponível em: <http://www.sbau.com.br/arquivos/1semestre2004.pdf>. Acesso em 30 mar. 2009.

CEMIG. Manual de arborização. Belo Horizonte: Fundação biblioteca nacional, 2004. 40 p.

COELBA. Guia de arborização urbana. Salvador: Venturie Gráfica e Editora, 2002. 55 p.

DANTAS, I. C.; SOUZA, C. M. C. Arborização urbana na cidade de Campina Grande - PB: Inventário e suas espécies. Revista de Biologia e Ciências da Terra. v.4, n.2, 2004.

IBGE. Cidades. Disponível em:<http://w.ibge.gov.br/cidadesat/topwindow.htm?1>Acesso em: 20 de fevereiro de 2002.

LIRA FILHO, J. A.; M. M. A. S. Impactos adversos na avifauna causados pelas atividades de arborização urbana. Revista de Biologia e Ciências da Terra. v.2, n.2, 2006.

LORENZI, H.; SOUZA, H.M. de; TORRES, M. A. V.; BACHER, L. B. Árvores exóticas no Brasil - madeireiras, ornamentais e aromáticas. São Paulo: Plantarum, 2003.

MALAVASI, U. C.; MALAVASI, M. M. Avaliação da arborização urbana pelos residentes estudo de caso em Marechal Cândido Rondon. Revista Ciência Florestal. v.11, n.1, p. 189 $-193,2001$.

OKAMOTO, J. Percepção ambiental e comportamento. São Paulo: Mackenzie, 2002.

OLIVEIRA, E.Z. A percepção ambiental da arborização urbana dos usuários da avenida Afonso Pena entre as ruas Calógeras e Ceará da cidade de Campo Grande-MS. 2005. 125 f. (Dissertação). UNIDERP, Campo Grande, 2005.

PÁDUA, S.; TABANEZ, M. (orgs.). Educação ambiental: caminhos trilhados no Brasil. São Paulo: Ipê, 1998. 
ROPPA, C; FALKENBERG, J. R; STANGERLIN, D. M; GIZELE, F; BRUN K; BRUN, E. J., LONGHI, S. J. Diagnóstico da percepção dos moradores sobre a arborização Urbana na Vila Estação Colônia - Bairro Camobi, Santa Maria - RS. Revista da Sociedade Brasileira de Arborização Urbana. v.2, n.2, p.11-30. 2007.

SANTOS, N. R. Z. dos; TEIXEIRA, I. F. Arborização de vias públicas: ambiente x vegetação. Porto Alegre: Palotti, 2001.

SECRETARIA MUNICIPAL DO MEIO AMBIENTE DE RIBEIRÃO PRETO/SP. Vamos Rearborizar Ribeirão Preto. Cartilha. 16 p.1995.

SILVA FILHO, D. F; PIVETTA K. F. L. Boletim acadêmico Série Arborização Urbana. Jaboticabal: UNESP/FCAV/FUNEP, 2002. 69p.

SITZ, R. A. A poda em árvores urbanas. In: 1ํㅡㄹ Curso em Treinamento sobre Poda em espécies Arbóreas Florestais e de Arborização Urbana. Piracicaba-SP, 1996

TRIGUEIRO, A. Meio ambiente no século 21: 21 especialistas falam da questão ambiental nas suas nas suas áreas de conhecimento. Rio de Janeiro: Sextante, 2003.

VOLPE-FILIK, A; SILVA, L. F. da; LIMA, A.M.L.P. Avaliação da arborização de ruas do bairro São Dimas na cidade de Piracicaba/SP através de parâmetros qualitativos. Revista da Sociedade Brasileira de Arborização Urbana, v.2, n.1. p.34-43. 2007. 